Sharif University of Technology
Scientia Iranica
SCIENTIA
IRAN I CA
Transactions A: Civil Engineering
www.scientiairanica.com

\title{
Satellite and ground-based assessment of Middle East meteorological parameters impact on dust activities in western Iran
}

\author{
A. Kermanshah ${ }^{\mathrm{a}, *}$, S. Sotoudeheian ${ }^{\mathrm{b}}$ and M. Tajrishy ${ }^{\mathrm{b}}$ \\ a. Department of Civil and Materials Engineering, University of Illinois at Chicago, Illinois, USA. \\ b. Department of Civil Engineering, Sharif University of Technology, Tehran, Iran.
}

Received 30 December 2014; received in revised form 20 July 2015; accepted 3 November 2015

\author{
KEYWORDS \\ Dust; \\ Meteorological \\ parameters; \\ Correlation analysis; \\ TOMS/AI; \\ Middle east.
}

\begin{abstract}
In this article, the relation between meteorological parameters and dust activities in western Iran has been studied. Satellite-based data achieved from TOMS are used to investigate the dust activities within a time period of 30 years. In the first part of this study, we examine the statistical trend of Aerosol Index (AI) and local meteorological parameters in 15 different stations. The same patterns of AI variations in all stations indicate that this region has always been subjected to dust storms which originate from similar sources in the neighboring countries that could be known as a sole dust transfer system. In the second part, we investigate the spatial correlation between the regional meteorological parameters in the Middle East and AI data to determine the contribution of meteorological parameters to dust levels. Broadly, results show that the precipitation in concurrent and antecedent months has a negative correlation with AI parameter of dusty months. Also, notably, we observed that the zonal wind speed in Iraq has a strong positive correlation with AI in our selected stations. This fact verifies that the zonal winds could be identified as the major cause of dust transfer system that was noted in the first part of this study.
\end{abstract}

(C) 2016 Sharif University of Technology. All rights reserved.

\section{Introduction}

In the last decade, increasing levels of Particulate Matters (PMs) have been investigated as a sophisticated issue that affects public health and surrounding environment in many developing countries. A portion of these pollutants are generated as a result of natural phenomena and human activities; some of them are generated as a result of secondary chemical reactions in the atmosphere $[1,2]$. Being constantly subjected to

*. Corresponding author. Tel.: +1 312 532-1174

E-mail addresses: akerma2@uic.edu (A. Kermanshah);

s_sotoudeheian@mehr.sharif.ir (S. Sotoudeheian);

tajrishy@sharif.edu (M. Tajrishy) these particulate matters has many negative effects on human health as it can cause respiratory ailments, cardiovascular diseases, and many additional problems. So far, numerous epidemiologic and toxicant studies have revealed a direct relation between the concentration of aerosols and their adverse health effects on human beings [3-6].

Aerosols can lead to an enormous change in the meteorological conditions and climate of a region. Depending on the physical properties of the particulates (i.e., shape and size of the particles), their composition and position of these aerosols in the atmosphere can either reflect sunlight off to space and make the Earth surface cooler or absorb the sunlight and make a region warmer [7]. 
In the previous decade, innovations in remote sensing techniques via satellites have made it possible to examine the air quality in a rapid and economical method [8]. Satellite remote sensing can undoubtedly play a significant role in monitoring environmental crises such as investigation of the dust activities. Many studies have demonstrated that atmospheric turbidity has a close relation to the amount of pollutants in the atmosphere of a region; therefore, Aerosol Index (AI) can be assumed as an important index in air quality assessments [9-15]. Meanwhile, the AI, which is an index of the amount of aerosols, can easily be retrieved by TOMS and OMI sensors. Given the fact that the TOMS measurements are performed in the ultraviolet (part of the electromagnetic spectrum), and UV albedo of the Earth's surface is low and virtually unchangeable, Herman et al. [14] realized that TOMS has the ability to precisely detect the aerosols above the Earth's surface.

The issue of dust activities has received considerable attention in recent years, and it is considered a fundamental environmental problem at international level. Due to the large scale of this phenomenon in each region and the ability of satellite sensors to collect information on a vast spatial scale, it is now more possible to study and evaluate the dust activities using satellite sensors. A great number of researchers attempted to investigate the changes in this phenomenon by means of satellite-related parameters and assessed its effects on hydrological and environmental conditions. Researchers then attempted to examine the qualitative relationship between the dust effect and climatic parameters. For instance, Ramanathan et al. [16] showed that the presence of aerosols in the atmosphere can weaken the hydrological cycle, which directly causes reduction in precipitation of a region. Prospero and Lamb [17] studied the winds which transferred a considerable amount of dust from Africa to the Atlantic and the Caribbean in the period of 1965-1998; they concluded that there is a negative correlation between the winds and the precipitation. Parallel to the aforementioned study, others showed that the dusts generated in arid and semi-arid regions played a crucial role in climatic changes of that region by changing the energy balance (this phenomenon is known as the aerosol direct effect) [18-20].

Many studies tried to show the effects of dust on climatic cycles in a quantitative way. By examining the variations of the aerosol index in North Africa and the Arabian Desert between 1979 and 1992, Barkan et al. [21] found that Lake Chad has had the highest amount of aerosol index in this period. The highest values of this index occurred in the summer months, namely May, June, and July. By using daily data of geo-potential height, wind, and July temperatures as well as TOMS-AI, Barkan et al. [22] demonstrated that the dust of North Africa was transported to Europe between 1979 and 1992. By evaluating TOMS data in the period of 1979-2000 for active dust-generating regions of North China, Xia et al. [15] showed that all regions with low altitude and precipitation are affected by dust activities. They showed that the highest value of AI occurs during spring, and that spring winds and precipitation play a dominant role in controlling dust activities. They concluded that the temperature and precipitation have a negative correlation with dust activities.

De Graaf et al. [23] showed that precipitation is related to dust loading in Africa, using the AI and daily precipitation measurements. Their results were an indication of the fact that the seasonal variations in the amount of aerosols depend upon monsoonal wet and dry periods in a definite manner. They indicated that precipitation and dust generation are negatively correlated. This result was not new; however, new AI data were used for the first time.

The presence of factors such as winds and storms (which are of the main causes to expedite soil erosion process), absence of sufficient humidity in soil, lack of adequate cohesion among soil particles, deficiency of vegetation, etc. are conditions for the occurrence of intensive dust storms [24-27]. Meanwhile, different meteorological parameters-especially wind speed, wind direction, relative humidity, and precipitationhave tremendous effects on the emergence of dust activities [28].

Each year, Iran, especially western part of the country, is subjected to severe dust storm intrusions. These dust particles emerge mostly from desert regions in neighboring countries, mainly Iraq, and increases PM levels in our target stations $[29,30]$. Using remote sensing data will provide us with a wealth of insights of dust activities. In spite of the importance of the dust activities, no comprehensive study has been done so far.

In this comprehensive study, the ground-based climate data and remote sensing methods are combined in order to investigate dust activities in western Iran and to perceive the effects of different meteorological parameters (i.e., precipitation, temperature, relative humidity, and wind speed), at local and regional scales, on the quantity of dust in that area. Satellite data in a 30-year period is extracted and their variation with other meteorological parameters is examined as a function of time at local scale. Furthermore, the influence of meteorological parameters, in large parts of the Middle East, on the occurrence of dust activities in western Iran is investigated by spatial correlation analysis.

\section{Methodology}

\subsection{Study region}

The study region is bounded in the west by the Red Sea, North Africa, in the east by the western 


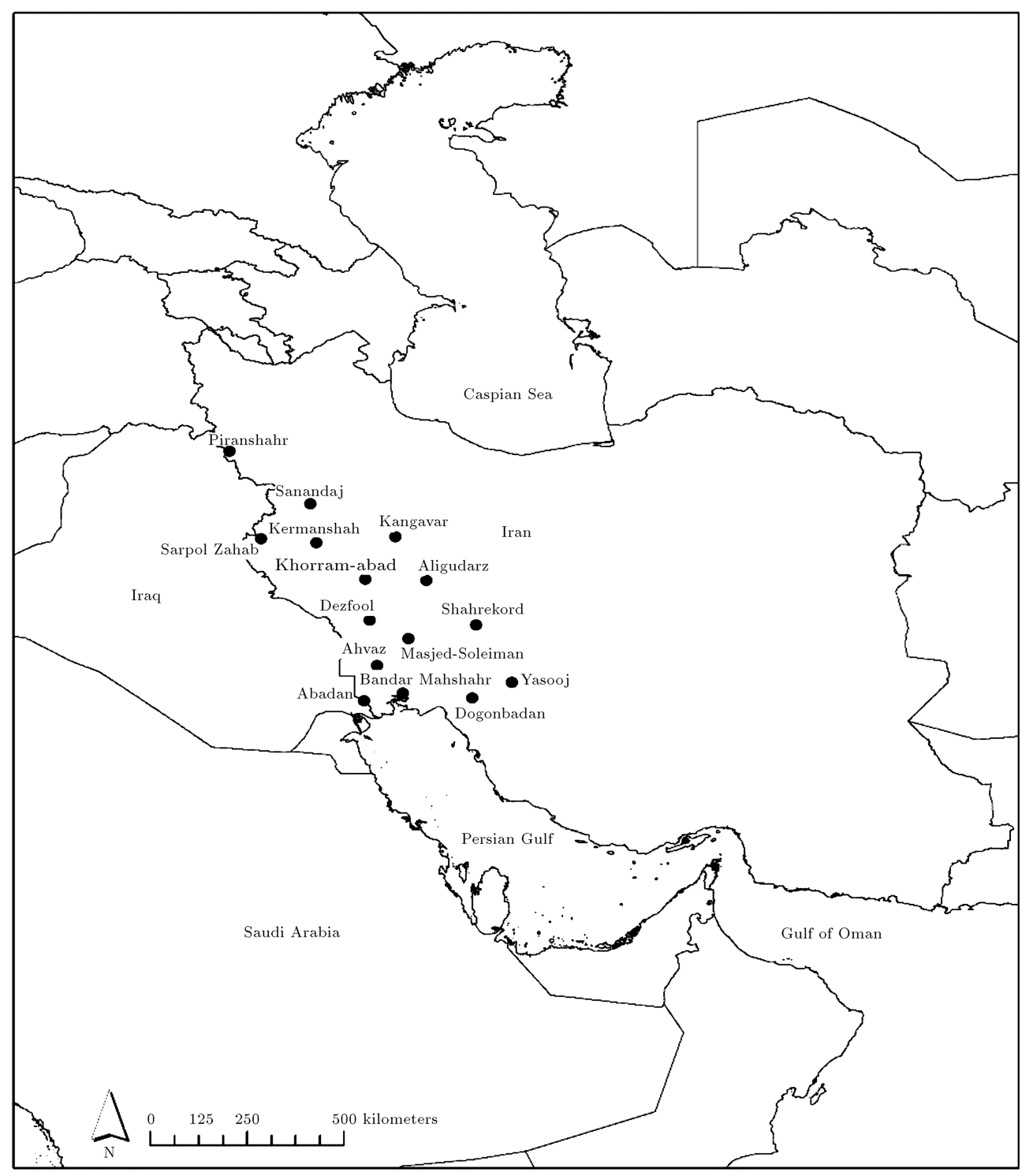

Figure 1. The stations in the study region.

part of Zagros Mountains, in the north by the Black Sea, and in the south by Saudi Arabia (Figure 1). Fifteen synoptic stations are selected in the region and are utilized to examine the relationship between the satellite data and meteorological parameters. The locations of the selected stations are shown in Figure 1.

\subsection{Meteorological parameters}

The parameters measured in synoptic stations, including precipitation, air temperature, relative humidity, wind velocity, number of days with visibility below or equal to 2 kilometers, and number of dusty-days, were extracted for the period of 1979-2008 from Iran Water Resources Management Company database. It is worth mentioning that the data of synoptic stations between the years 1979-2008 are used for the first part of this research. As other researchers have been shown before, meteorological parameters such as those selected in this study could have a positive or negative relation with each other and also with satellite data. Of course, degree of linear dependency between the parameters is different in various parts of the world. During warm seasons, the Earth's surface warms up and heats the surrounding air which creates pressure gradient that leads to an increase in wind speed. In parallel, the quantity of precipitation and relative humidity decrease in the warm seasons and reach their lowest levels.

According to these inter-relations between meteorological parameters, it is expected that similar relations would exist between these parameters and dust indicators retrieved from satellites. Therefore, it could be concluded that in the warm seasons, the increase of wind speed from threshold friction velocity generates a suspended bulk of particles that causes dust storms in a region. However, threshold friction velocity is highly depended on different factors such as 
soil texture, vegetation, and humidity. For instance, a decreasing trend in relative humidity will decrease threshold friction velocity due to the soil desiccation and loss of vegetation cover which eventually results in formation of dust storm more easily. Moreover, precipitation causes wet deposition of particles and decrease of dust intensity in an area. Hence, decrease of precipitation in the warm seasons may lead to increase of particle concentrations and satellite-driven dust indicators values. Relative humidity has the same influence as precipitation. Given all these facts, there is a need to investigate the degree of correlation between different meteorological and dust parameters in our study region.

To observe the existing correlation between the AI and meteorological parameters, regional data is employed based on the interpolation of the measured data from 1500 ground stations by using optimum interpolation algorithm from the NCEP/NCAR 40year reanalysis project database [31].

\subsection{AI data from TOMS and OMI sensors}

Total Ozone Mapping Spectrometer (TOMS) sensor was launched on Nimbus 7 (N7) satellite in 1978. TOMS provides a long-term record of satellite-based observations of many parameters, such as total ozone (in regional and global scales), volcanic $\mathrm{SO}_{2}, \mathrm{AI}$, and tropospheric aerosols, and many other daily dust measurements. TOMS monitors a strip of 50 to $200 \mathrm{~km}$ perpendicular to its orbit [14]. In 2004, the Ozone Monitoring Instrument (OMI) sensor was launched on Aura Satellite, one of the satellites of A-Train collection of satellites, after four successfully flown TOMS instrument in space (N7 (1978-1993), Meteor-3 (19911994), Earth Probe (July 1996-current), and ADEOS (1996-1997)). This sensor continues the goal of TOMS and measures and records the aerosol properties.

\subsubsection{Definition of Aerosol Index (AI)}

TOMS uses a spectral contrast method in the UV region, where the ozone absorption is very low, to retrieve Aerosol Index (AI). AI is a qualitative indicator of the existence of UV absorbing particles (e.g., dust and smoke) for determining the amount of aerosols in the atmosphere. This index is obtained based on a spectral contrast between $340 \mathrm{~nm}$ and $380 \mathrm{~nm}$ wavelengths in the UV part of the spectra [14] and can be defined as follows [32]:

$$
\mathrm{AI}=-100\left[\log _{10}\left(\frac{I_{340}}{I_{380}}\right)_{\text {meas }}-\log _{10}\left(\frac{I_{340}}{I_{380}}\right) \text { calc }\right],
$$

where:

$$
\left(\frac{I_{340}}{I_{380}}\right)_{\text {meas }}: \begin{aligned}
& \text { the ratio of the measured } 340 \text { and } 380 \\
& \text { nm TOMS/OMI radiances }
\end{aligned}
$$

$$
\begin{aligned}
\left(\frac{I_{340}}{I_{380}}\right)_{\text {calc }}: & \text { the ratio of the calculated } 340 \text { and } \\
& 380 \mathrm{~nm} \text { TOMS/OMI radiances for } \\
& \text { a Rayleigh atmosphere assuming a } \\
& \text { constant surface albedo [33]. }
\end{aligned}
$$

As mentioned before, due to nearly constant UV surface albedo, sensor can easily distinguish absorbing particles over land surface [14]. The data and images of TOMS sensor have spatial resolution of $1.25 \times 1$ degree, and those of OMI have a spatial resolution of $1 \times 1$ degree. The AI is positive for absorbing aerosols and negative for non-absorbing aerosols (pure scattering) [33,34]. For absorbing aerosols, the AI number depends on the size distribution of the particles, optical properties, and the altitudes of absorbing aerosols [35]. The greater value for this index indicates that we have more absorption by aerosols in the atmosphere of that region [36].

\subsubsection{Extraction and collection of $A I$ in stations}

The AI data from TOMS and OMI sensors were collected from NASA via the website: http://toms. gsfc.nasa.gov. The data extraction stage was conducted for the 15 stations under study for a period of 30 years from 1979 to 2008 on a daily basis. Unfortunately, the data for 1994-1995 are not available; yet for other years, the data can be used to figure out monthly and annual averages of aerosol index.

\section{Results}

3.1. Variations in synoptic parameters and AI The general trends of variations in AI were roughly the same in all stations within the 30 -year period (Figure 2) with only degrees of variation differing in the stations. For instance, all stations showed a decline in the AI from 2003 and an increase in 2006. This issue is the indicator of the fact that the whole of western Iran is subjected to dust outbreaks, originates from the same major dust sources. These sources that are located in the western neighboring countries of Iran (i.e., Iraq, Saudi Arabia, and Syria) are the main sources of dust particles in Middle Eastern regions which could affect the stations in our study area [29]. By the change in the amount of dust generation from these origins, dust intensity will change in the study region $[36,37]$.

Among the 15 selected stations, Abadan, Bandar Mahshahr, and Ahwaz experienced the highest mean annual AI, i.e. between 1.2 and 2, in this 30-year period in the study period. All of these stations are located in Khuzestan Province in the southern part of the western Iran. This fact shows a more frequent presence of dust activities in southern regions of study area that have been affected by regional and local dust sources.

According to one previous study in western Iran 


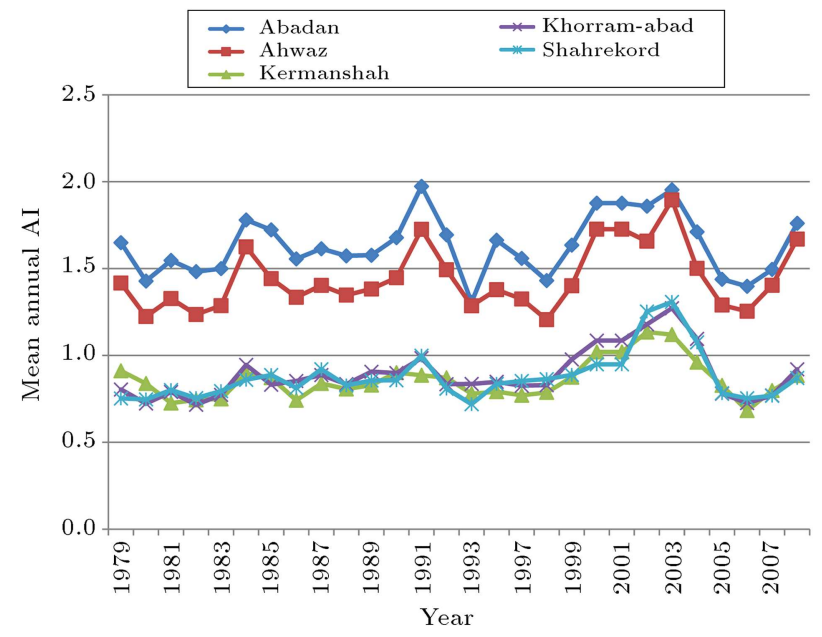

(a)

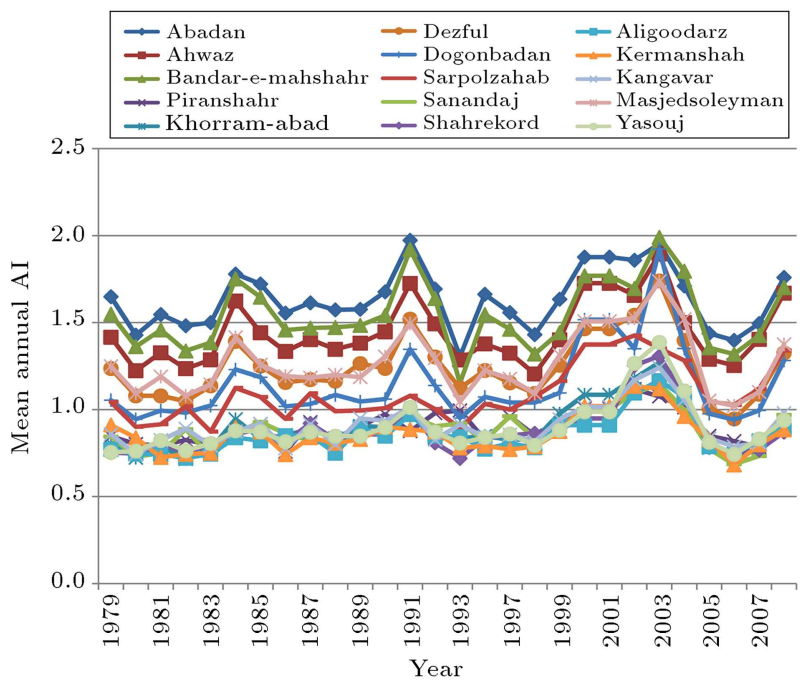

(b)

Figure 2. Mean annual Aerosol Index (AI) for the years 1979-2008; (a) In 15 stations of Western Iran; and (b) in 5 selected stations, Abadan, Ahwaz, Kermanshah, Khorram-abad, and Shahrekord.

between those 15 selected stations, comprehensive trend analysis, i.e. non-parametric tests of MannKendall and Spearman's Rho and parametric test of linear regression, showed that only five stations of Abadan, Ahwaz, Kermanshah, Khorram-abad, and Shahrekord had significant climatic variables changes; therefore, in this study, the investigations are followed in these five stations [38]. According to Figure 2, among the five selected stations, the variations of the AI in Kermanshah, Khorram-abad, and Shahrekord, which had lower AI compared to Abadan and Ahwaz stations (between 0.68-1.31), had been small and approximately similar and have had a constant trend in all these years, except in the years 2001-2004. Abadan and Ahwaz stations were the most influenced by dust activities; therefore, they can be assumed as two distinguished stations in the study of dust activities occurrence.

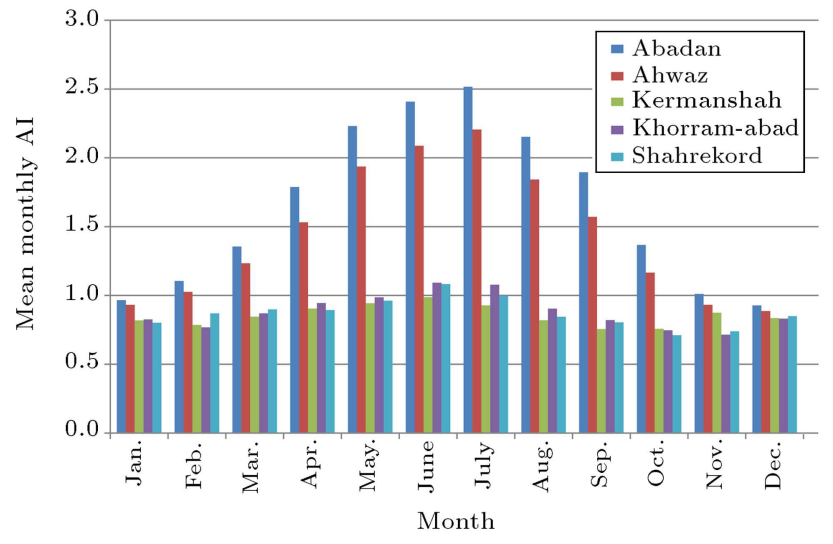

Figure 3. Mean monthly Aerosol Index (AI) in the 5 selected stations, Abadan, Ahwaz, Kermanshah, Khorram-abad, and Shahrekord, for the years 1979-2008.

By evaluating the average monthly variation of the AI in the five selected stations during the study period (Figure 3), it becomes evident that the highest amounts of aerosols occurred during the months of May, June, and July. Furthermore, the average precipitation was approximately zero in June and July for the two stations (Figure 4(a)) with the AI of these stations being between 1.8 and 2.6 in these months. However, maximum AI for the three stations of Kermanshah, Khorram-abad, and Shahrekord never exceeds 1.1 .

The values of six meteorological parameters related to the five selected stations for the years 19792008 are shown in Figure 4. These results indicate that Abadan and Ahwaz have very different trends in all of the meteorological parameters, except relative humidity.

According to the type and graining of the regional soil, wind threshold velocity for occurrence of severe storms in the region is $3 \mathrm{~m} / \mathrm{s}$ (equal to $10 \mathrm{~km} / \mathrm{hr}$ ) [10], while Abadan and Ahwaz stations experience winds with more average speeds in May, June, and July. This confirms the existence of many dusty days in these two stations. Another prominent remark is the coincidence of severe storms in the region with the increase in the average number of dusty days in a month and the days with visibility less than $2 \mathrm{~km}$ (Figure 4(d)-(f)). Overall, as the weather gradually becomes warmer (Figure $4(\mathrm{~b})$ ), and the precipitation reduces (Figure 4(a)), average wind speed increases (Figure 4(e)). This event generates an increasing dust density and causes the dust to remain in the atmosphere (Figure 3).

\subsection{The investigation of correlation between AI and synoptic parameters}

In this section, the interaction of dust indicator (AI) and meteorological data in the selected stations are examined. As it will be shown later, the results of 


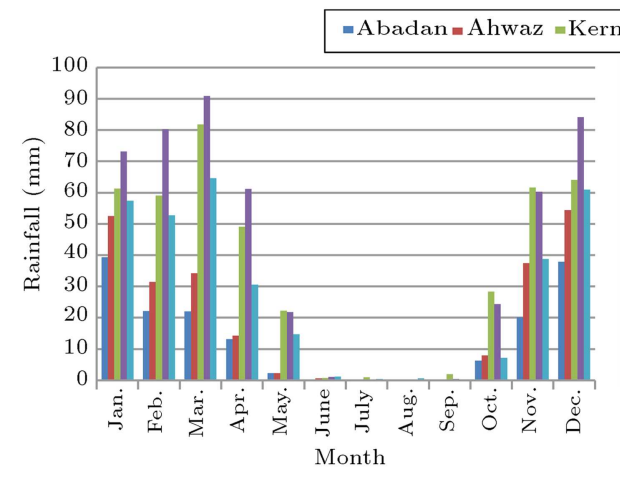

(a)

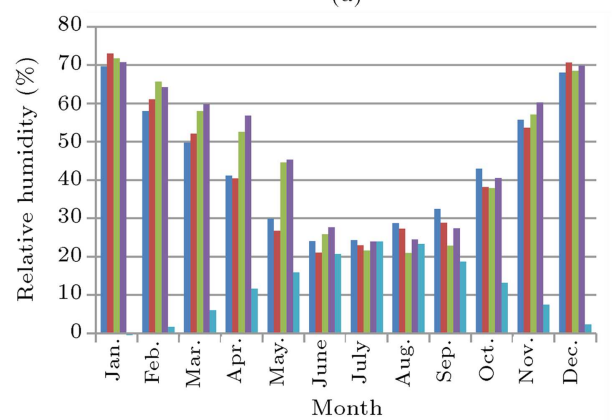

(c)

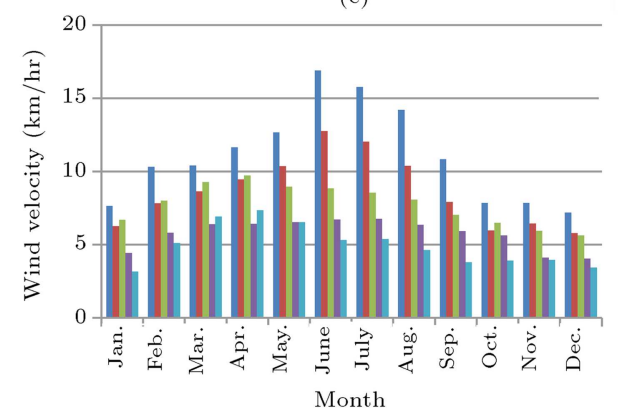

(e)

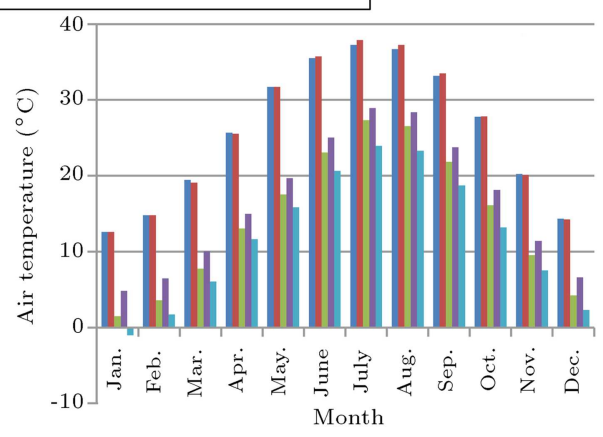

(b)

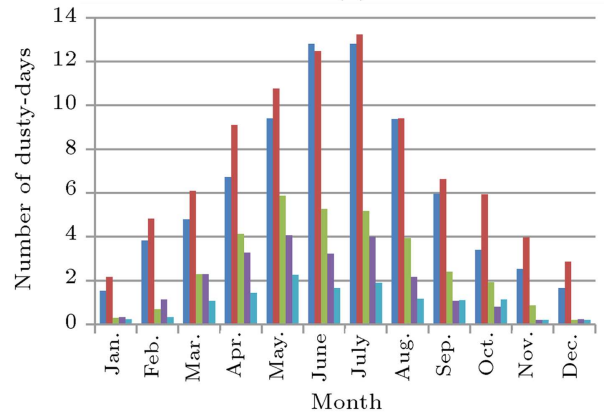

(d)

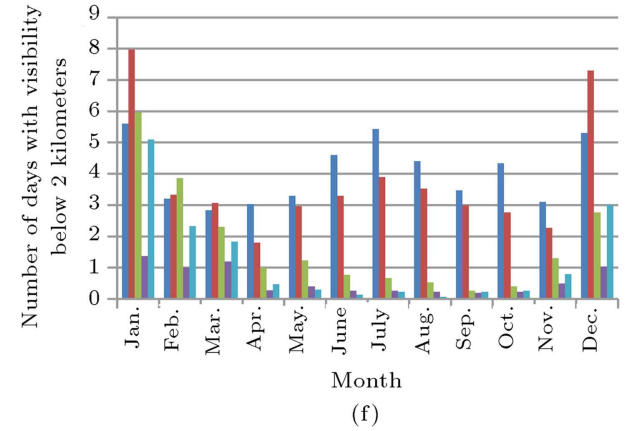

Figure 4. (a) Mean rainfall values in similar months. (b) Mean air temperature values. (c) Mean relative humidity values. (d) Mean number of dusty-days values. (e) Mean wind velocity values. (f) Mean number of days with visibility below 2 kilometers values in 5 selected stations, Abadan, Ahwaz, Kermanshah, Khorram-abad, and Shahrekord, for the years 1979-2008.

Ahwaz and Abadan stations are more tangible since $\mathrm{AI}$ is higher in these stations.

By comparison of monthly average temperature and AI (Figure 5), we observe that the variations of these two parameters are similar to each other, and they have a direct relationship. High values of $R^{2}$ in the two stations of Abadan $\left(R^{2}=0.687\right)$ and Ahwaz $\left(R^{2}=\right.$ $0.599)$ are the indicator of the mutual interaction of dust and temperature variations with each other. This issue confirms that May, June, and July, which are the hottest months (Figure 4(b)), are the dustiest months as well (Figure 3). Given the large number of figures regarding the mutual relationship of $\mathrm{AI}$ and synoptic parameters, only the diagram of temperature and $\mathrm{AI}$ is presented. The results of other synoptic parameters are presented in the text and also in Table 1. In the following, the results of other parameters will be examined.
In general, there is a negative correlation between the two parameters of monthly average precipitation and AI; the months in which there is high precipitation; rain drops reduce the volume of aerosols in atmosphere. The studies have demonstrated that in all stations, the increase in precipitation has reduced the AI; however, this trend in all stations is not similar to the one in Abadan $\left(R^{2}=0.224\right)$ and Ahwaz $\left(R^{2}=0.241\right)$. This negative trend is evident in these two stations.

Another meteorological parameter being compared with AI is the relative humidity. The results reveal that there is a negative correlation between these two parameters. As was expected, the months in which aerosols are substantial in the atmosphere and the AI is high, relative humidity of the stations are low. Generally, increase in relative humidity could have effect on particles adhesion to the soil, and subsequently an increase in threshold friction velocity. Therefore, 

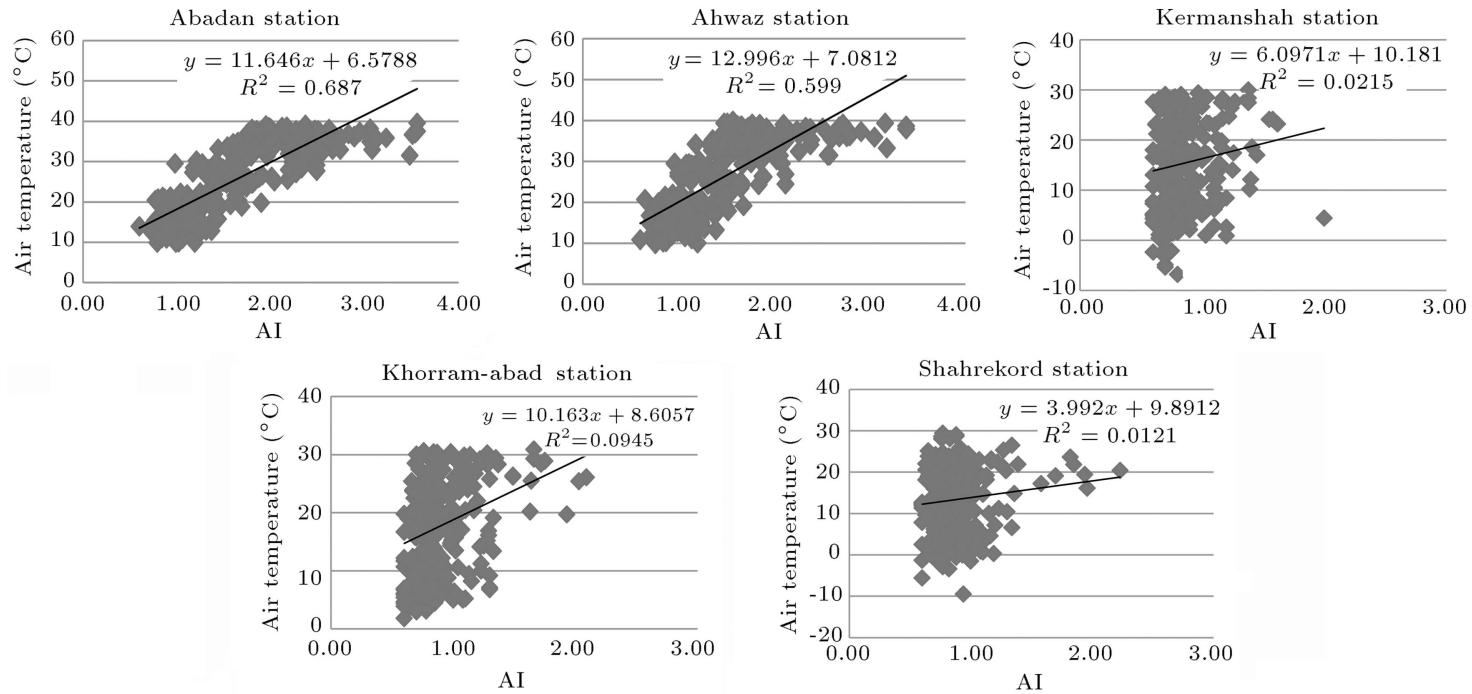

Figure 5. Correlation coefficient between mean air temperatures with Aerosol Index (AI) in 5 selected stations, Abadan, Ahwaz, Kermanshah, Khorram-abad, and Shahrekord, for the years 1979-2008.

Table 1. Correlation coefficients $\left(R^{2}\right)$ between meteorological parameters and AI for 5 selected stations.

\begin{tabular}{cccccc}
\hline Meteorological parameters & Abadan & Ahwaz & Kermanshah & Khorram-abad & Shahrekord \\
\hline Mean monthly precipitation & 0.22 & 0.24 & $<0.01$ & 0.04 & $<0.01$ \\
Mean monthly air temperature & 0.69 & 0.60 & 0.02 & 0.1 & 0.01 \\
Mean monthly relative humidity & 0.73 & 0.61 & $<0.01$ & 0.08 & 0.03 \\
$\quad$ Mean monthly wind velocity & 0.45 & 0.35 & 0.04 & 0.01 & 0.11 \\
Mean monthly number of days with & $<0.01$ & 0.01 & 0.02 & 0.1 & 0.01 \\
visibility below or equal to 2 km & & & & & 0.03 \\
Mean monthly number of dusty-days & 0.18 & 0.25 & $<0.01$ & & \\
\hline
\end{tabular}

lifting of particles becomes difficult. Thus, in the low relative humidity conditions, aerosol particles could be generated more easily and AI parameter could have higher values. This issue is more evident in Abadan station $\left(R^{2}=0.725\right)$ and Ahwaz station $\left(R^{2}=0.605\right)$.

Like monthly average temperature, monthly wind speed data has a positive correlation with AI. This correlation was stronger in the two stations of Abadan $\left(R^{2}=0.449\right)$ and Ahwaz $\left(R^{2}=0.346\right)$ in comparison with the others. According to Figure 4(e), the average wind velocity of the stations between 1979 and 2005 was higher in May, June, July, and August. In fact, when wind speed has a higher value than threshold friction velocity, possibility of dust storm generation is further.

The comparison between monthly variations in the number of dusty days and the number of days with visibility less than $2 \mathrm{~km}$ with the AI, as well as monthly averages of these parameters during the 30-year statistical period (Figure 4(d) and (f)), shows that there is a positive correlation between the number of dusty days in a month and the AI in Ahwaz and Abadan stations. AI is an indicator of dust and increase in dust intensity in a region will cause an increase in number of dusty days; therefore, the obtained results were completely expected. Due to the lack of any ground level measurements of satellite data in Iran, this could be a useful alternative method to check and validate the extracted data from satellite instruments.

\subsection{Analysis of dust-generating factors in the study region}

In this section, the existing correlation between meteorological parameters of precipitations, temperature, relative humidity, wind speed (zonal and meridional winds), and AI were examined (these five series of meteorological data were chosen after extended survey of 16 climatic variables).

For determining the key factors in the occurrence of dust storms in the region, the correlation analysis was performed for AI time series of Abadan and Ahwaz stations (due to similarity of the results, figures will only be presented for Abadan station). Both stations are subjected to dust activities according to the results obtained in the previous sections and some meteorological data collections for the region. This was determined by the correlation data and maps 


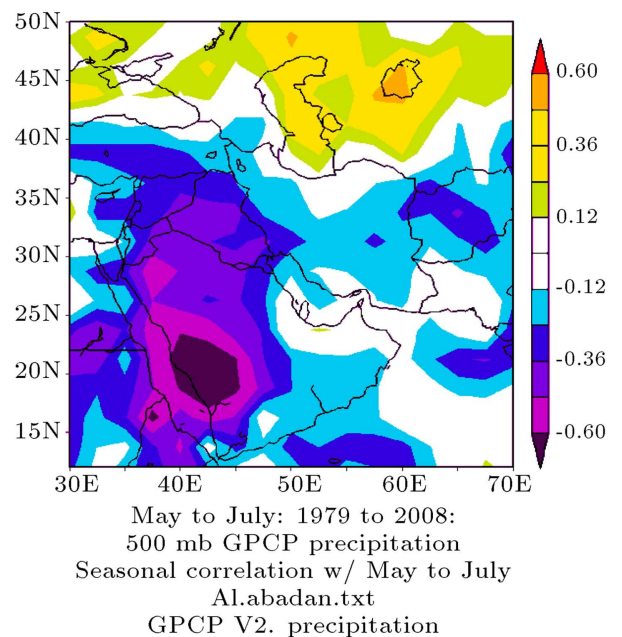

(a)

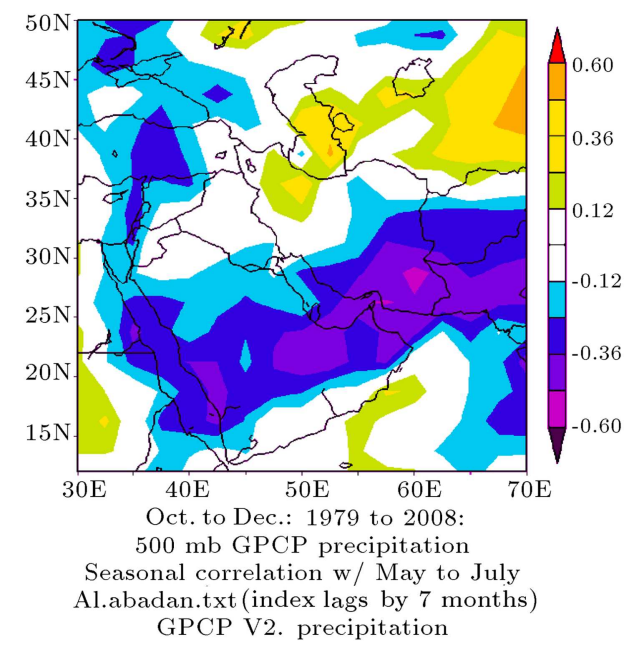

(c)

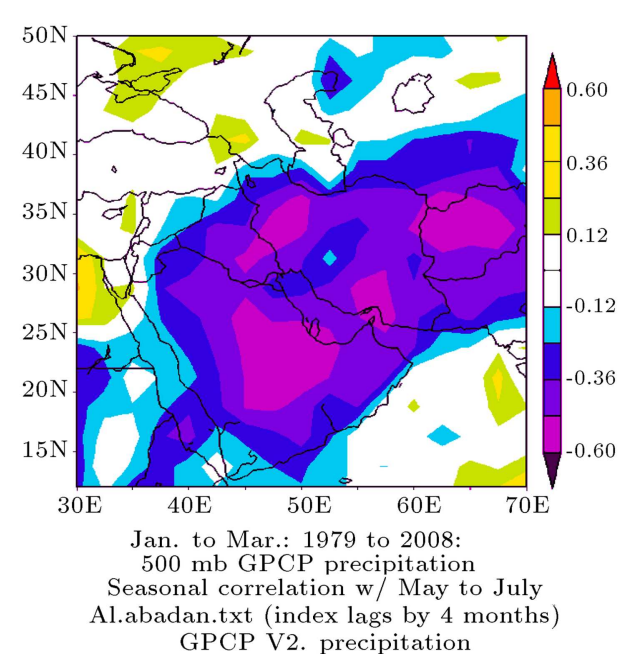

(b)

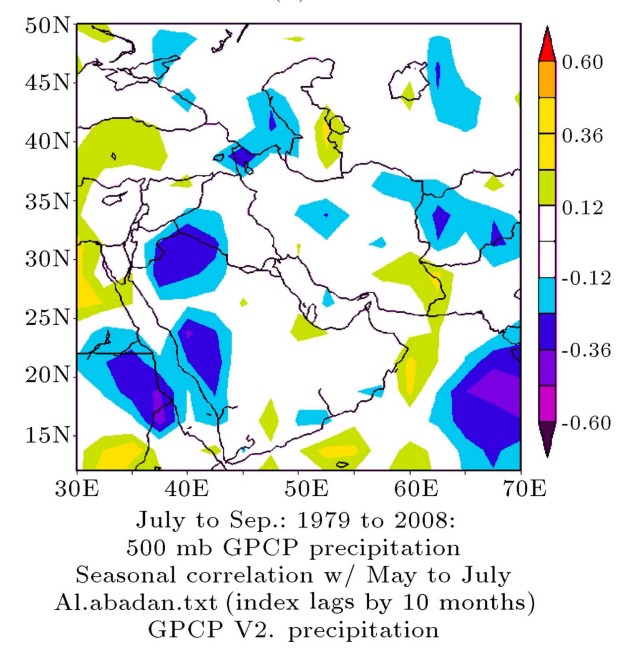

(d)

Figure 6. Spatial distribution map of correlation between Aerosol Index (AI) of Abadan station (May-July) with rainfall between 1979-2008: (a) Concurrent months; (b) 4-month lag, antecedent winter; (c) 7-month lag, antecedent autumn; and (d) 10-month lag, antecedent summer.

provided by the US National Oceanic and Atmospheric Administration (NOAA).

It is worth mentioning that the information on time series of precipitation, temperature, relative humidity, as well as zonal and meridional wind speeds is acquired through National Centers for Environment Prediction-Department Of Energy (NCEP-DOE) data set [31].

\subsubsection{Correlation between $A I$ and precipitation}

Precipitation due to its impact on dust intensity, i.e. by increasing wet deposition as a physical effect, could have a significant relation with AI data. As aforementioned, AI reaches its maximum in May, June, and July. The presence of a correlation relation between AI in these months in Ahwaz and Abadan stations and the four periods of precipitation are examined (Figure 6). Selection of these time series for precipitation data (with time delay of 4,7 , and 10 months) are for finding a correlation between the precipitations in every season within a year by AI data. According to the statistical period of AI data for Abadan and Ahwaz stations, from 1979 to $2008,95 \%$ confidence level for significant correlation is 0.36 .

The AI of Abadan station in dusty months and precipitation in the concurrent months (Figure 6(a)) are negatively correlated in the study region. Confidence level of this negative correlation is higher than $95 \%(r=0.36)$ in a vast area of Saudi Arabia, parts of Syria and Jordan, Southern and Central Iraq, and Western Yemen. In the second period of precipitation, antecedent winter (Figure 6(b)), the negative correlation between the precipitation and AI seems to be stronger and valid in a wider area, such that the whole region has a correlation factor with confidence level of $95 \%$. The chief remark in the second period is that the precipitation of the Eastern part of the regionIran, Afghanistan, and Pakistan-also has a strong 


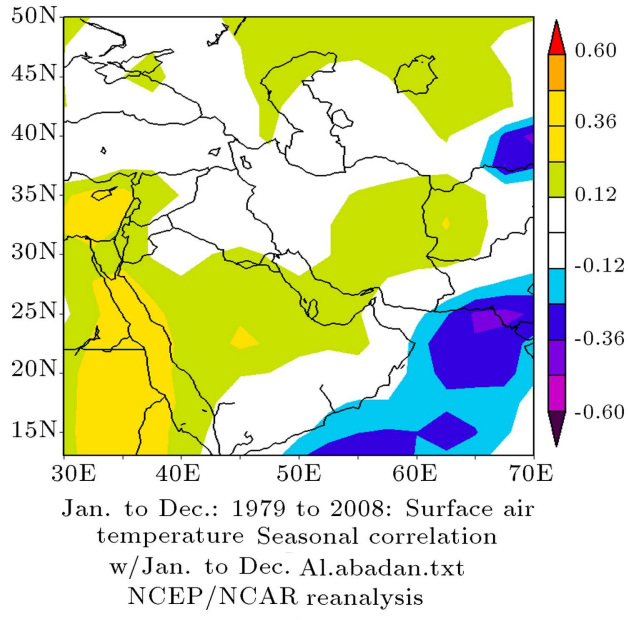

(a)

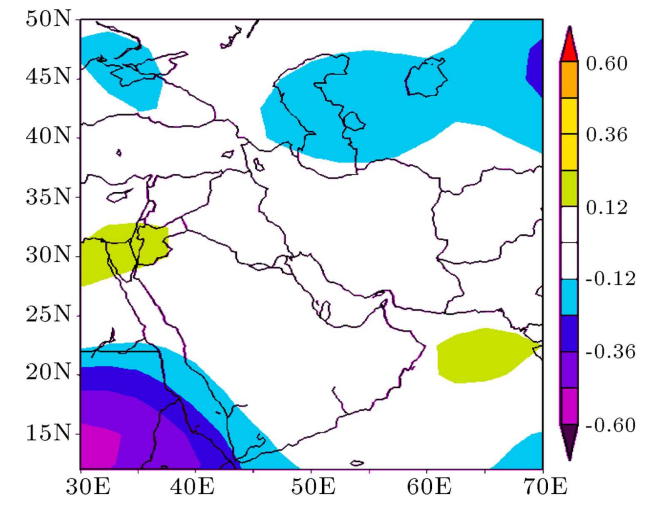

Jan. to Dec.: 1979 to 2008: $500 \mathrm{mb}$ air temperature Seasonal correlation w/ Jan. to Dec. Al.abadan.txt NCEP/NCAR reanalysis

(b)

Figure 7. Spatial distribution map of correlation between Aerosol Index (AI) of Abadan station with air temperature between 1979-2008: (a) On the earth surface; and (b) at altitude of $500 \mathrm{mb}$.

correlation with AI of Abadan station. In the third period of precipitation, i.e. antecedent autumn, there is a negative correlation between the precipitation and AI similar to the two previous periods. However, this correlation is weaker in Iraq and northern Arabia, while it is stronger in southern and southeastern Iran, parts of Oman Desert, and southern Arabia (Figure 6(c)).

In the fourth period, the correlation of the last summer precipitation with May, June, and July AI is observed to be positive and weak ( $r$ lower than 0.24 ) in some small and scattered parts, and negative and weak ( $r$ lower than 0.36 ) in regions such as southeastern Iraq (Figure 6(d)). This shows the instability of local distribution of the correlations and weakness of the relation between the antecedent summer precipitation and the dust generated the next year.

Correlation analysis for Ahwaz station showed that the trends are the same as that of Abadan station, and a translational motion is seen for a region with a negative correlation in these four periods of precipitation which moves from Iraq and Arabian Deserts to the east of the study region. The difference is that the Ahwaz station has a stronger negative correlation than the Abadan station. According to the results, the assumption of negative effects of precipitation on dust concentration in the region is confirmed. With the strong negative correlation (with $95 \%$ confidence level or higher) between the concurrent summer precipitation and antecedent winter precipitation with $\mathrm{AI}$, in most parts of the region, we can conclude that the antecedent autumn precipitation, especially precipitations in Iraq, can play a crucial role in controlling aerosols and dust activities in the western Iran. Notably, antecedent autumn conditions could have influence on some effective parameters that increase the dust activity such as soil humidity, vegetation cover, and so forth.

\subsubsection{Correlation between $A I$ and temperature}

Temperature on the Earth's surface is one of the major factors in controlling dust activities; temperature has a direct relation with AI. As seen in Figure 7(a), the temperature of a large portion of the Arabian Desert, eastern and central Iran, parts of northeastern Africa, and West Bank has a direct relation with aerosols of Abadan station. As the temperature increases in these regions, the aerosols observed in Abadan station (AI) also increase. This positive correlation is significant in some regions, especially a wide region over the Red Sea and a small area in Saudi Arabia $\left(23^{\circ} \mathrm{N}-45^{\circ} \mathrm{E}\right)$. In Ahwaz station, similar to Abadan station, a positive correlation is observed in the whole region. However, the difference is that the confidence level of this direct correlation is more than $95 \%$ in a vast area of the Arabian Desert. It is worth mentioning that in each of the two stations, as we go higher from ground level, the correlation becomes insignificant. This can be observed in Figure $7(\mathrm{~b})$ for the altitude of $500 \mathrm{mb}$ which is approximately located in the middle of the troposphere. Since dust storms develop from deserts in the neighboring countries and transport to the study area of a low height, investigation of relation between air temperature and AI parameter at altitude of $500 \mathrm{mb}$ do not show any significant correlation. Moreover, high surface air temperature will increase soil desiccation, and due to existence of most part of particles near the surface, the correlation between surface air temperature and AI is more significant [29].

\subsubsection{Correlation between $A I$ and the relative humidity}

As it is expected, the AI has a negative correlation with the relative humidity in Abadan and Ahwaz stations. Examinations have revealed that the relative humidity on the Earth's surface has a negative correlation with 


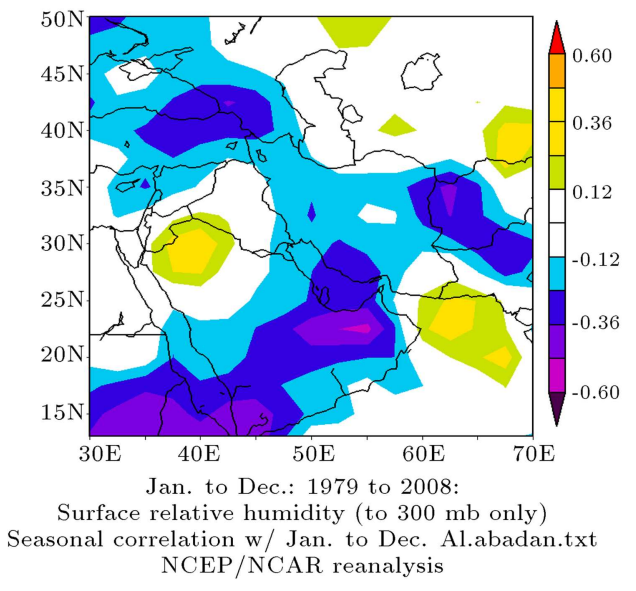

(a)

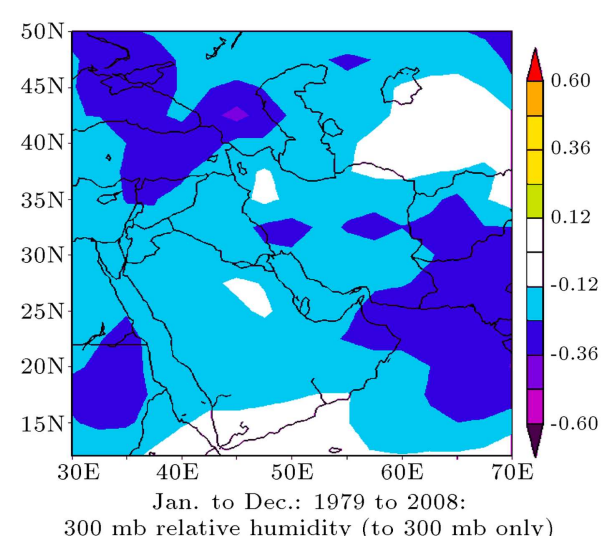

Seasonal correlation w/ Jan. to Dec. Al.abadan.txt NCEP/NCAR reanalysis

(b)

Figure 8. Spatial distribution map of correlation between Aerosol Index (AI) of Abadan station with relative humidity between 1979-2008: (a) On the earth surface; and (b) At altitude of $300 \mathrm{mb}$.

the AI in all regions except a vast area in northern Saudi Arabia (Figure 8(a)). This issue is also valid with regard to the Ahwaz station. The difference is that the strength of the significant negative correlation is stronger in four regions: large areas of Turkey, western Iraq, southern Iran, and western Pakistan, in Ahwaz station compared to Abadan station $(-0.6 \leq r \leq-0.36)$.

$\mathrm{AI}$ and relative humidity at the altitude of $300 \mathrm{mb}$ were examined for the two stations (Figure 8(b)). It became evident that at higher altitudes, there is a negative correlation between relative humidity and AI, which becomes widespread. There is not a region with significant confidence level of $95 \%$ in Abadan station. In Ahwaz station, there is a significant negative correlation $(r \leq 0.36)$ between relative humidity and AI in some parts of the study region like in Turkey and Syria.

\subsubsection{Correlation between AI and wind speed (zonal and meridional winds)}

The results revealed that May, June, July, and August are the months in which the average wind speed is high (Figure 4(e)). The average wind speed in the whole region during these months differs significantly from average annual wind speed. For example, average wind speed in Iraq is $3-4.5 \mathrm{~m} / \mathrm{s}$ for these months, which is two times the annual wind speed. A noteworthy remark here is the wind direction in these months, which blows toward south stations of western areas of Iran. Nevertheless, the annual wind direction is different from these months and is toward southern directions (Figure 9).

According to the increase in average wind speed in the study region in recent years, the variations in the average wind speed in the periods of 1979-2008 and 1999-2008 are examined in Figure 9. As evident from the figure, the average wind speed in eastern Mediterranean Sea has increased in recent years, and this increase has expanded to the east, Iraq. This issue is observed in three regions of central and eastern Iran, a vast area over the Caspian Sea, and the region near Iran, Iraq, and Turkey borders. This increase is between $0.2 \mathrm{~m} / \mathrm{s}$ and $1.5 \mathrm{~m} / \mathrm{s}$ in these regions, and this issue can partially validate the assumption that the increase in average wind speed on the Earth's surface in May, June, July, and August is one of the reasons of dust generation.

In addition to the undeniable role of wind speed parameter in transportation of dust particles from their origins to different parts of a region [29], wind direction determines the path in which particles would be transported. In order to consider the wind direction in our analysis, we use NCEP/NCAR data that have categorized quantity of wind speed into two wind speed vectors in $x$ and $y$ directions [31]. Zonal wind is represented by $U_{x}$ as $x$ component of wind velocity and meridional wind is shown by $V_{y}$ as $y$ component of wind speed. Therefore, the direction of wind flow is considered in this study using these terms.

Here, by examining the relation between the average zonal wind speed and AI of the two Abadan and Ahwaz stations (Figure 10), we can realize the positive correlation between zonal winds on the Earth's surface in the dusty months of May, June, and July as well as the AI in the regions of central Iran, Iraq, and south of the Persian Gulf. This means that the average zonal wind speed on the Earth's surface in the mentioned four regions in May, June, and July plays a major role in the increase or reduction of dust in Abadan and Ahwaz stations. Given the fact that the movement of a huge amount of the dust above humid winds occurs in the Planetary Boundary Layer (PBL) (between $600 \mathrm{mb}$ and $800 \mathrm{mb}$ altitudes) [22], the studies show that by going from the lower to upper levels, there is a significant positive correlation (with confidence level of $95 \%$ for some regions) in a vast 


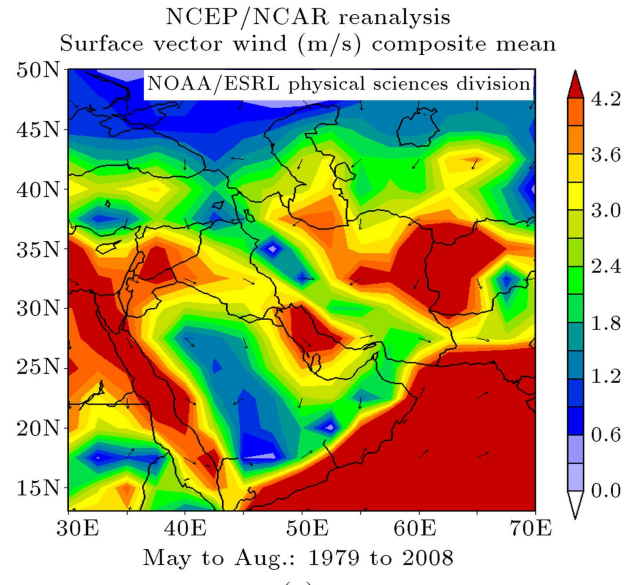

(a)

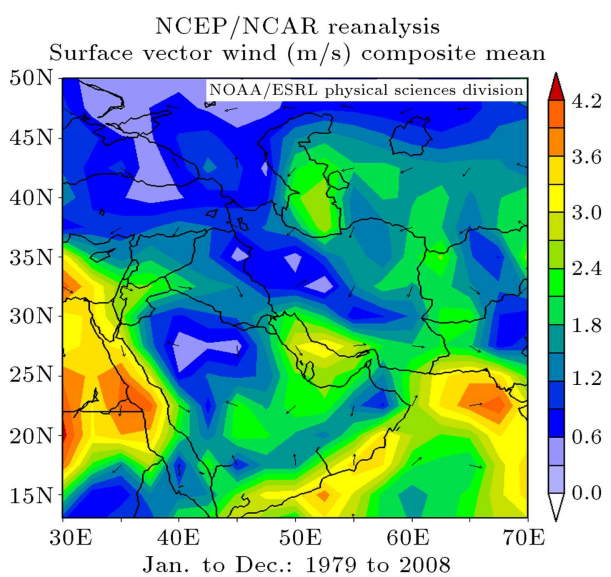

(b)

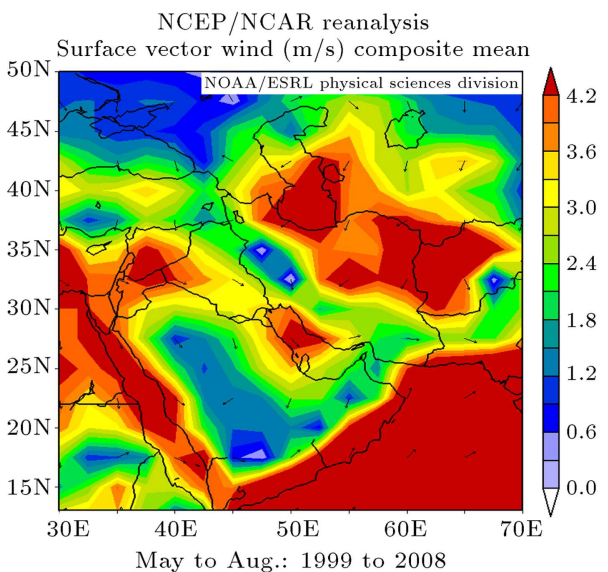

(c)

Figure 9. Spatial distribution map of mean wind velocity variability on the earth surface: (a) During 1979-2008 in the period of May-August; (b) during 1979-2008 in the whole year; and (c) during 1999-2008 in the period of May-August.

area in Iraq, Syria, Western Banks, and northern Saudi Arabia. This means that as the zonal wind speed increases in May, June, and July at higher altitudes, these winds transfer more dust to Abadan and Ahwaz stations from the aforementioned regions and cause the AI to increase in the two stations (Figure 10(c)-(e)).

In addition to noting the impact of zonal winds on the increase or decrease of AI value in the region, examining the effect of meridional winds on AI is another aspect of the problem which should be considered. According to Figure 11(a), it is observed that the average meridional wind speed on the Earth's surface has not had a definite and uniform relation in the whole study region with the AI in Abadan and Ahwaz stations. Three centers in northern and northeastern parts of Iran, a part of northern Arabia, and Turkey have a significant negative correlation (with confidence level of $95 \%$ ) with the AI of the stations. Nevertheless, the average meridional wind speed of the eastern part of the study region, southern, and eastern Iran and a vast area over the Oman Gulf have a significant positive correlation with the AI. By noting the increase at altitude and movement toward higher levels, it is observed that two correlative flows, one positive and the other negative, exist in eastern and western parts of the study region between the average meridional wind speed and AI in both Abadan and Ahwaz stations which increase in higher levels (Figure 11(c)-(e)). Therefore, achieving a definitive result regarding the presence of a specific correlation between meridional wind speed and AI is not possible.

Overall, the results obtained in this study are akin to some outcomes of previous works. It is noteworthy to mention that although most parts of Iran are frequently exposed to dust storms, comprehensive studies on these issues using meteorological factors and satellite-based data have not been performed yet. Ramanathan et al. [16] demonstrated that dust aerosol outbreak can cause suppression of rainfall in a region which leads to a less efficient removal of pollutants. Prospero and Lamb [17] observed that wind parameter was an effective factor to transfer particles from dust origins to different parts of study area and affirmed that dust loads have strong negative correlation with prioryear precipitation. As a quantitative work, Barkan et al. [21] pointed out that the highest value of AI 


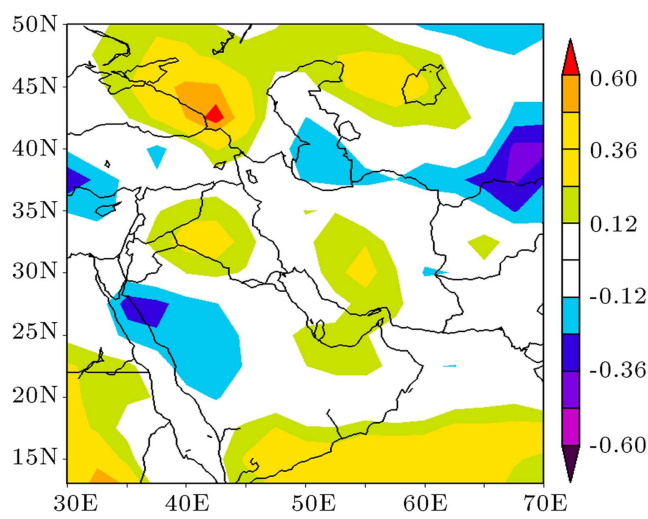

May to July: 1979 to 2008: Surface zonal wind Seasonal correlation w/ May to July Al.abadan.txt NCEP/NCAR reanalysis

(a)

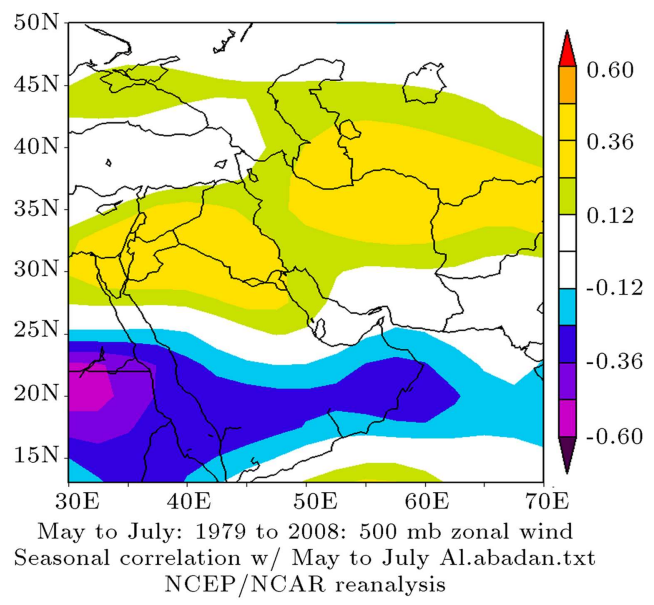

(c)

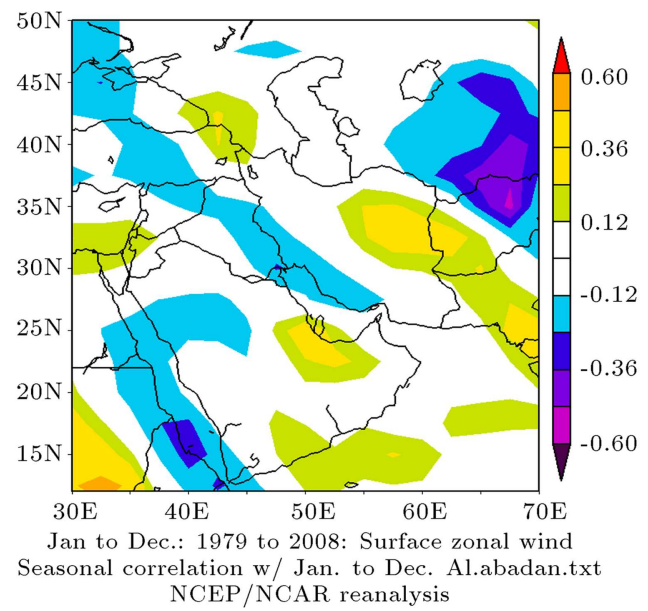

(b)

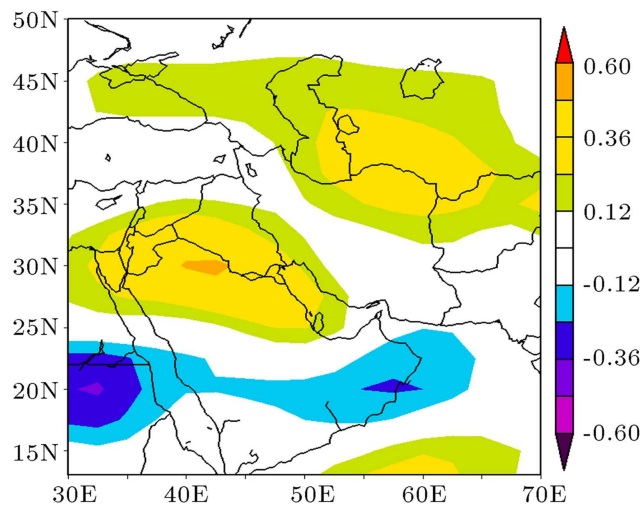

May to July: 1979 to 2008: $600 \mathrm{mb}$ zonal wind Seasonal correlation w/ May to July Al.abadan.txt NCEP/NCAR reanalysis

(d)

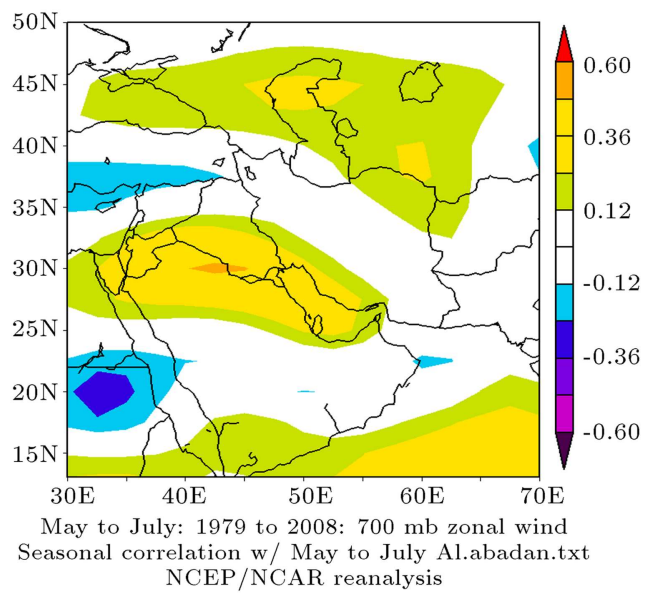

(e)

Figure 10. Spatial distribution map of correlation between Aerosol Index (AI) of Abadan station with zonal wind velocity between 1979-2008: (a) On the earth surface in May, June, and July; (b) on the earth surface in the whole year; (c) at altitude of $500 \mathrm{mb}$ in May, June, and July; (d) $600 \mathrm{mb}$ in May, June, and July; and (e) at altitude of 700 mb in May, June, and July.

occurred in summer months. Moreover, Xia et al. [15] observed that in controlling dust activities, spring wind and precipitation in previous rainy season played a significant role.

In this comprehensive study on dust activities, we showed that western parts of Iran have always been subjected to a dominant dust transfer system which increases by going from the northern parts to the southern regions, proving the fact that the southern regions are closer to the dust sources which are located 


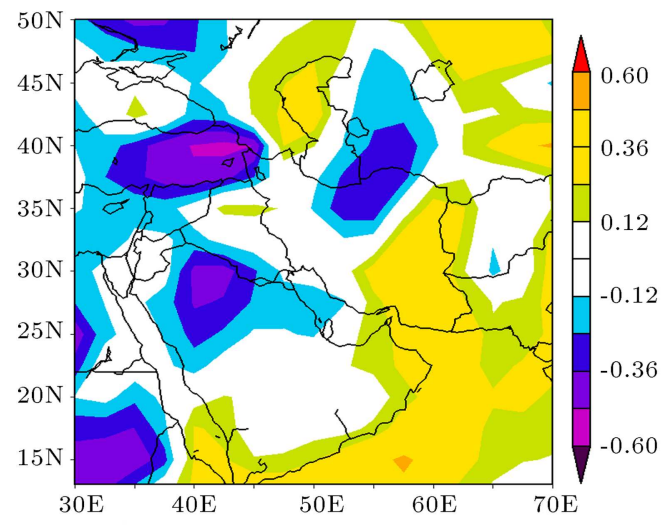

May to July: 1979 to 2008: Surface meridional wind Seasonal correlation w/ May to July Al.abadan.txt NCEP/NCAR reanalysis

(a)

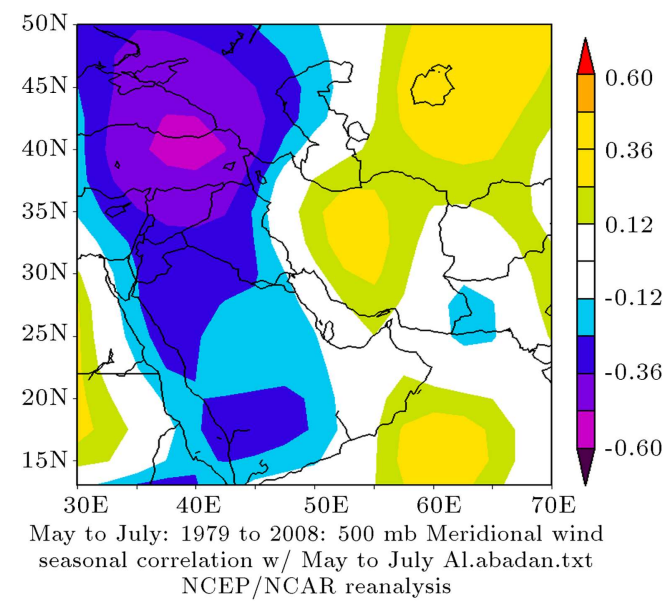

(c)

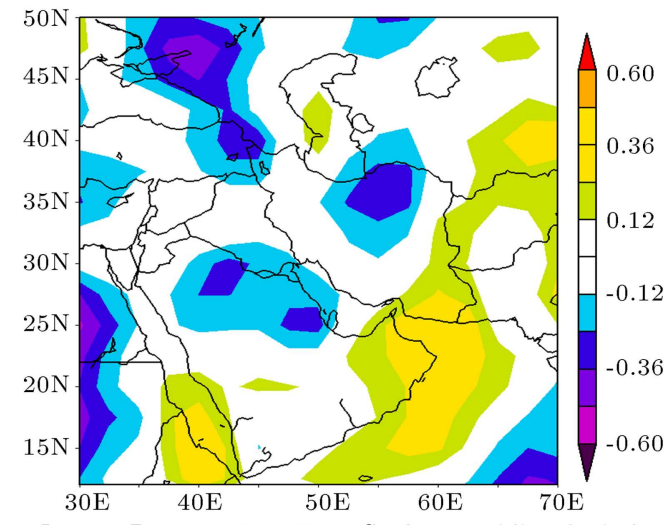

Jan. to Dec.: 1979 to 2008: Surface meridional wind Seasonal correlation w/ Jan. to Dec. Al.abadan.txt $\mathrm{NCEP} / \mathrm{NCAR}$ reanalysis

(b)

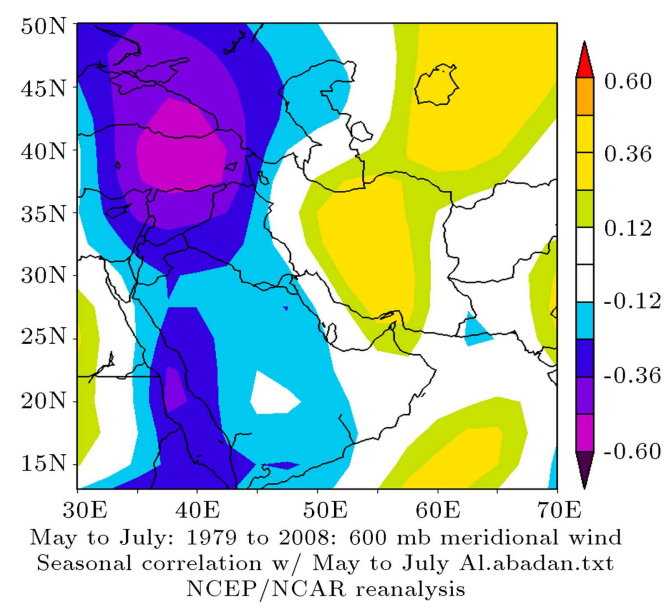

(d)

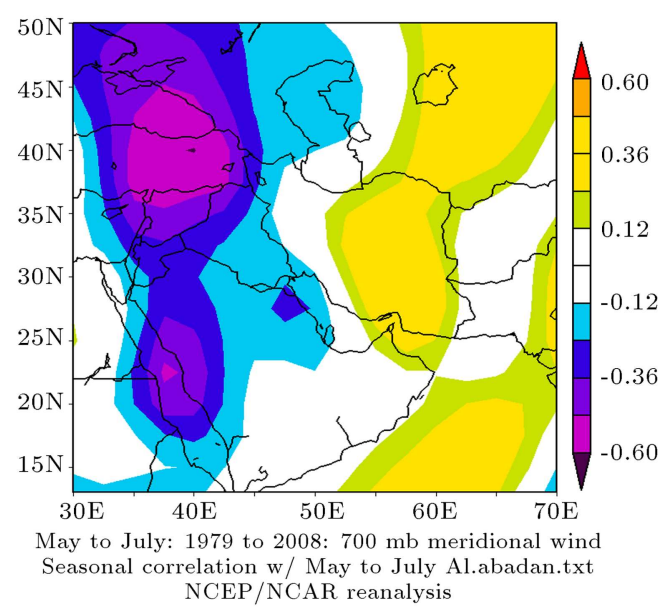

(e)

Figure 11. Spatial distribution map of correlation between Aerosol Index of Abadan station with meridional wind velocity between 1979-2008: (a) On the earth surface in May, June, and July; (b) On the earth surface in the whole year; (c) at altitude of $500 \mathrm{mb}$ in May, June, and July; (d) $600 \mathrm{mb}$ in May, June, and July; and (e) 700 mb in May, June, and July.

in the neighboring countries. Moreover, results of spatial correlation between the regional meteorological parameters in the Middle East and AI data of the two selected stations (i.e., Abadan and Ahwaz) showed that the precipitation in concurrent and antecedent months has a significant negative correlation with AI parameter of dusty months. Furthermore, we observed that the zonal wind speed in Iraq has a significant positive correlation with AI in our stations. Also, a positive correlation exists between monthly average 
temperature and AI of the whole year. Moreover, a negative correlation between average monthly relative humidity and AI was observed, which was stronger in a wider area at higher altitudes. In addition, zonal winds in Iraq were one of the main factors of dust transfer system to Iran.

\section{Conclusion}

The main goal of this study is to evaluate the relation between local and regional meteorological parameters with dust activities by means of satellite-bases data, i.e. TOMS instrument data, in western Iran. The results reveal that due to the exact same variations of $\mathrm{AI}$ in the 15 stations in western Iran, this region is always subjected to one main dust transfer system that originates from similar sources in the neighboring countries many times during this period. The effect of this dominant dust transfer system on western Iran is accentuated while going from the north to the south, suggesting the fact that the southern parts of the country are closer to the source of the dust transfer system.

Moreover, results show that most of the dust activities in region occur during May, June, and July. At the same time, the precipitation is almost zero in these months, which validates the contention that the precipitation can play a substantial role in controlling the dust activities in the stations.

Overall, our investigations show that in summer, increase of air temperature corresponds to decrease of average precipitation; increase of wind speed due to the high pressure gradient and descending trend in relative humidity values (i.e., strong positive correlation between the temperature and AI; negative correlation between the precipitation and AI; strong negative correlation between the relative humidity and AI; and fairly strong positive correlation between the wind speed and AI). Generally, threshold friction velocity is associated with relative humidity parameter; decrease of soil humidity and vegetation cover results in a decrease in threshold friction velocity. Simultaneously, in summer, wet deposition of particles decreases due to a reduction in quantity of precipitation. Therefore, particles get blown apart from soil more easily and increase the possibility of dust storm formation where the wind speeds are higher than the threshold friction velocity.

The correlation analysis, related to selected stations of Ahwaz and Abadan, between monthly meteorological data in the study region and AI showed that the rain precipitation in spring, winter, and autumn plays a central role in controlling particulates in stations. The results show a negative correlation between the concurrent precipitation and AI of the dusty months in the Arabian Desert, a negative correlation in the antecedent winter in the whole study region, and a negative correlation in the antecedent autumn in the southern Arabian Desert as well as southern and southeastern Iran.

Moreover, the examination of the parameter of monthly average temperature in the whole year with the AI showed that there is a positive correlation between these two parameters in a vast part of the Arabian Desert, eastern, and central parts of Iran, some parts of northwestern Africa and West Bank. With increase in temperature, the degree of this positive correlation also reduces. In addition, a negative correlation between average monthly relative humidity and AI of the stations was seen except for a vast area in Northern Arabia, which is stronger and observed in a wider area at higher altitudes. The results of correlation analysis between zonal and meridional winds and AI of the stations in these months testified that there is a direct correlation between the zonal wind speed on the Earth's surface in Iraq and the AI of the stations. In other words, the cause of that dominant dust transfer system is zonal winds that transfer dust particles from their source in Iraq's desert and bring them to western regions of Iran.

Finally, given that these behaviors were only seen in Ahwaz and Abadan and not in all other western stations of Iran, we cannot reach an impeccable conclusion for the hypothesis of climate change due to dust activities in western Iran.

\section{Acknowledgment}

The authors would like to give special thanks to the Iran Water Resources Management Company for providing the meteorological data used in this study. Also, the authors express their gratitude to Mr. S. Wasim Tayyeb for developing a program for extracting AI data of the stations from the available dataset.

\section{References}

1. World Health Organization, Air Quality Guidelines for Europe, (2nd Ed.), WHO regional publications. European series; no. 91 (2000).

2. World Health Organization, Health Aspects of Air Pollution with Particulate Matter, Ozone and Nitrogen Dioxide, Bonn, Germany, 13-15 January 2003 (2003).

3. Atkinson, R.W., Ross Anderson, H., Sunyer, J., et al. "Acute effects of particulate air pollution on respiratory admissions: results from APHEA 2 project", American Journal of Respiratory and Critical Care Medicine, 164(10), pp. 1860-1866 (2001).

4. Brunekreef, B. and Forsberg, B. "Epidemiological evidence of effects of coarse airborne particles on health", European Respiratory Journal, 26(2), pp. 309318 (2005). 
5. Pope III, C.A. and Dockery, D.W. "Health effects of fine particulate air pollution: lines that connect", $J$. Air Waste Manag. Assoc., 56(6), pp. 709-742 (2006).

6. Samoli, E., Analitis, A., Touloumi, G., et al. "Estimating the exposure-response relationships between particulate matter and mortality within the APHEA multicity project", Environ. Health Perspect., 113(1), pp. 88-95 (2005).

7. Washington, R., Todd, M., Middleton, N.J. and Goudie, A.S. "Dust-storm source areas determined by the total ozone monitoring spectrometer and surface observations", Ann. Assoc. Am. Geogr., 93(2), pp. 297-313 (2003).

8. Al-Saadi, J., Szykman, J., Pierce, R.B., et al. "Improving national air quality forecasts with satellite aerosol observations", Bull. Am. Meteorol. Soc., 86(9), pp. 1249-1261 (2005).

9. Chu, D.A., Kaufman, Y., Zibordi, G., Chern, J., Mao, J., Li, C. and Holben, B. "Global monitoring of air pollution over land from the earth observing systemterra moderate resolution imaging spectroradiometer (MODIS)", J. Geophys. Res. Atmospheres, 1984-2012, 108(D21) (2003).

10. Esmaili, O., Tajrishy, M. and Arasteh, P.D. "Results of the 50 year ground-based measurements in comparison with satellite remote sensing of two prominent dust emission sources located in Iran", Proc. SPIE 6362, Remote Sensing of Clouds and the Atmosphere XI, 636209 (October 12, 2006). DOI: 10.1117/12.692989.

Presented at Remote Sensing, International Society for Optics and Photonics, 636209-636209 (2006).

11. Gupta, P. and Christopher, S. "Seven year particulate matter air quality assessment from surface and satellite measurements", Atmospheric Chem. Phys., 8(12), pp. 3311-3324 (2008).

12. Péré, J.-C., Pont, V., Mallet, M. and Bessagnet, B. "Mapping of PM10 surface concentrations derived from satellite observations of aerosol optical thickness over south-eastern France", Atmospheric Res., 91(1), pp. 1-8 (2009).

13. Wang, J. and Christopher, S.A. "Intercomparison between satellite-derived aerosol optical thickness and PM2. 5 mass: implications for air quality studies", Geophys. Res. Lett., 30(21) (2003).

14. Herman, J., Bhartia, P., Torres, O., Hsu, C., Seftor, C. and Celarier, E. "Global distribution of UV-absorbing aerosols from Nimbus 7/TOMS data", J. Geophys. Res. Atmospheres, 1984-2012, 102(D14), pp. 1691116922 (1997).

15. Xia, XA, Liang, F. and Wang, M. "Evaluation of dust activity and climate effects in North China", $J$. Environ. Sci., 16(2), pp. 187-190 (2004).

16. Ramanathan, V., Crutzen, P., Kiehl, J. and Rosenfeld, D. "Aerosols, climate, and the hydrological cycle", Science, 294(5549), pp. 2119-2124 (2001).

17. Prospero, J.M. and Lamb, P.J. "African droughts and dust transport to the Caribbean: Climate change implications", Science, 302(5647), pp. 1024-1027 (2003).
18. Tegen, I. "Modeling the mineral dust aerosol cycle in the climate system", Quat. Sci. Rev., 22(18), pp. 18211834 (2003).

19. Huang, J., Lin, B., Minnis, P., Wang, T., Wang, X., Hu, Y., Yi, Y. and Ayers, J.K. "Satellite-based assessment of possible dust aerosols semi-direct effect on cloud water path over East Asia", Geophys. Res. Lett., 33(19) (2006).

20. Slingo, A., Ackerman, T.P., Allan, R., et al. "Observations of the impact of a major Saharan dust storm on the atmospheric radiation balance", Geophys. Res. Lett., 33(24) (2006).

21. Barkan, J., Kutiel, H. and Alpert, P. "Climatology of dust sources in North Africa and the Arabian Peninsula, based on TOMS data", Indoor Built Environ., 13(6), pp. 407-419 (2004).

22. Barkan, J., Alpert, P., Kutiel, H. and Kishcha, P. "Synoptics of dust transportation days from Africa toward Italy and central Europe", J. Geophys. Res. Atmospheres, 1984-2012, 110(D7) (2005).

23. De Graaf, M., Tilstra, L., Aben, I. and Stammes, P. "Satellite observations of the seasonal cycles of absorbing aerosols in Africa related to the monsoon rainfall, 1995-2008", Atmos. Environ., 44(10), pp. 1274-1283 (2010).

24. Reheis, M. "A 16-year record of eolian dust in Southern Nevada and California, USA: Controls on dust generation and accumulation", J. Arid Environ., 67(3), pp. $487-520$ (2006).

25. Yu, B., Hesse, P. and Neil, D. "The relationship between antecedent regional rainfall conditions and the occurrence of dust events at Mildura, Australia", $J$. Arid Environ., 24(2), pp. 109-124 (1993).

26. Zou, X.K. and Zhai, P.M. "Relationship between vegetation coverage and spring dust storms over northern China", J. Geophys. Res. Atmospheres, 1984-2012, 109(D3) (2004).

27. Huang, F. and Gao, Q. "Climate controls on dust storm occurrence in Maowusu desert, Inner Mongolia, North China", J. Environ. Sci., 13(1), pp. 14-21 (2001).

28. Csavina, J., Field, J., Félix, O., Corral-Avitia, A.Y., Sáez, A.E. and Betterton, E.A. "Effect of wind speed and relative humidity on atmospheric dust concentrations in semi-arid climates", Sci. Total Environ., 487, pp. 82-90 (2014).

29. Givehchi, R., Arhami, M. and Tajrishy, M. "Contribution of the Middle Eastern dust source areas to PM 10 levels in urban receptors: case study of Tehran, Iran", Atmos. Environ., 75, pp. 287-295 (2013).

30. Sotoudeheian, S. and Arhami, M. "Estimating groundlevel PM10 using satellite remote sensing and groundbased meteorological measurements over Tehran", $J$. Environ. Health Sci. Eng., 12(1), p. 122 (2014). 
31. Kalnay, E., Kanamitsu, M., Kistler, R., et al. "The NCEP/NCAR 40-year reanalysis project", Bull. Am. Meteorol. Soc., 77(3), pp. 437-471 (1996).

32. Hsu, N.C., Herman, J., Torres, O., Holben, B., Tanre, D., Eck, T., Smirnov, A., Chatenet, B. and Lavenu, F. "Comparisons of the TOMS aerosol index with sun-photometer aerosol optical thickness: Results and applications", J. Geophys. Res. Atmospheres, 19842012, 104(D6), pp. 6269-6279 (1999).

33. Torres, O., Bhartia, P., Herman, J., Ahmad, Z. and Gleason, J. "Derivation of aerosol properties from satellite measurements of backscattered ultraviolet radiation: Theoretical basis", J. Geophys. Res. Atmospheres, 1984-2012, 103(D14), pp. 17099-17110 (1998).

34. Varotsos, C., Ondov, J., Cracknell, A., Efstathiou, M. and Assimakopoulos, M. "Long-range persistence in global aerosol index dynamics", Int. J. Remote Sens., 27(16), pp. 3593-3603 (2006).

35. Mahowald, N.M. and Dufresne, J. "Sensitivity of TOMS aerosol index to boundary layer height: Implications for detection of mineral aerosol sources", Geophys. Res. Lett., 31(3) (2004).

36. Prospero, J.M., Ginoux, P., Torres, O., Nicholson, S.E. and Gill, T.E. "Environmental characterization of global sources of atmospheric soil dust identified with the Nimbus 7 total ozone mapping spectrometer (TOMS) absorbing aerosol product", Rev. Geophys., 40(1), pp. 2-1 (2002).

37. Ginoux, P., Prospero, J.M., Gill, T.E., Hsu, N.C. and Zhao, M. "Global-scale attribution of anthropogenic and natural dust sources and their emission rates based on MODIS deep blue aerosol products", Rev. Geophys., $\mathbf{5 0}(3)$ (2012).

38. Kermanshah, A. "Investigation of dust-causing factors in western Iran and its effects on climate changes", Master's Thesis, Sharif University of Technology (2011).

\section{Biographies}

Amirhassan Kermanshah received his BSc and MSc degrees from Sharif University of Technology and is currently a $\mathrm{PhD}$ candidate in University of Illinois at Chicago, USA. His research interests include the resilience of cities and urban networks to extreme events.

Saeed Sotoudeheian was born in Tonekabon, Iran, in 1987. He received his BSc and MSc degrees from School of Civil Engineering, Sharif University of Technology in 2009 and 2011, respectively. Currently, He is a PhD candidate at SUT. His main areas of research interest are application of remote sensing by satellite in air pollution over megacities.

Massoud Tajrishy is a Professor of Civil Engineering, Founder and Director of the Environment and Water Research Center (EWRC) in Sharif University of Technology. He received his PhD from University of California at Davis, and his research interests include water quality management and application of remote sensing in water resources engineering. 